\title{
AN ACCURACY ASSESSMENT OF GLOBAL NAVIGATION SATELLITE SYSTEM WILDLIFE-TRACKING COLLARS IN THE SOUTHERN CHILEAN PATAGONIA
}

\author{
UNA EVALUACIÓN DE LA PRECISIÓN DEL SISTEMA DE NAVEGACIÓN DE \\ SATÉLITES EN EL SEGUIMIENTO DE ANIMALES SILVESTRES USANDO \\ COLLARES GPS EN EL SUR DE LA PATAGONIA CHILENA
}

Kirstin Lawrence-Apfel ${ }^{1}$, Thomas H. Meyer ${ }^{1}$, Kazi Arifuzzaman ${ }^{1}$ \& Isaac M. Ortega ${ }^{1}$

\begin{abstract}
RESUMEN
En el Parque Nacional Torres del Paine hemos evaluado la precisión de tres tipos de collares diferentes. Los collares utilizan los sistemas de navegación global mediante satélites (GNSS) y se utilizan en el seguimiento de la fauna salvaje. La evaluación fue determinada comparando las posiciones del collar en relación con coordenadas de control establecidas previamente y con posiciones muy precisas. Las coordenadas de control las establecimos utilizando receptores portadores de observación GNSS de doble frecuencia y comparando estas posiciones de alta precisión con las de relativamente baja precisión, de frecuencia única, de un solo código de seguimiento en dos escenarios: (i) pruebas estacionarias: tres collares de tres fabricantes diferentes fueron evaluados mediante marcadores de control permanente, $\mathrm{y}$ (ii) pruebas itinerantes: el collar de un fabricante se evaluó en ambientes utilizados por animales portadores de collar. Estos ambientes incluyen tres tipos de hábitats con topografía y copas de los árboles que pudieran aumentar la obstrucción del contacto con los satélites. Los resultados estacionarios muestran que incluso en condiciones ideales, hay diferencias estadísticamente significativas en la precisión media de la posición entre los collares, pero que estas diferencias son pequeñas en comparación con el tamaño de los rangos de hogar de los tipos de animales a los que se les equiparía con collar. La evaluación del muestreo itinerante demostró que bajo el cielo abierto, los errores promedio fueron consistentes con las afirmaciones del fabricante, pero que las distancias del error medio y el fallo de corregir los errores (fallo en la colección de posiciones en horarios establecidos) aumentó con según se incrementa la obstrucción del cielo.
\end{abstract}

Palabras clave: Sistema de navegación global con el uso de satélites (GNSS), Parque Nacional Torres del Paine, evaluación de precisión de GPS, collares GPS para fauna silvestre.

1 Department of Natural Resources \& the Environment, University of Connecticut, 1376 Storrs Rd. Unit 4087, Storrs, CT. 06269-4087, USA. morty.ortega@uconn.edu. 


\section{ABSTRACT}

The accuracies of three different global navigation satellite system (GNSS) wildlife-tracking collars were assessed in Torres del Paine National Park in Southern Patagonia, Chile by comparing collarderived positions against high-accuracy control coordinates. We established control coordinates using dual-frequency, carrier-phase observing GNSS receivers and then compared these high-accuracy positions with the relatively low-accuracy, single-frequency, code-only wildlife-tracking collar positions in two scenarios: (i) stationary testing: three different manufacturers' collars were assessed on permanent control markers, and (ii) roving testing: one manufacturer's collar was assessed throughout Torres del Paine National Park in places wildlife might take the collar, including three habitats with increasing skyobstructing topography and tree canopy. The static results show that, even under ideal conditions, there are statistically significant differences in mean positional accuracy among the collars, but these differences are small compared to the size of the home ranges of the types of animals that would be fitted with a collar. The roving assessment showed that, under open sky, the average errors were consistent with the manufacturer's claims, but mean-error distances and fix failures (failure to collect a scheduled position) increased with increasing sky obstruction.

Key words: Global Navigation Satellite System (GNSS), Torres del Paine National Park, GPS accuracy assessment, GPS wildlife tracking collars.

\section{INTRODUCTION}

The promise of GNSS positioning (positioning is the activity of determining the three spatial coordinates, i.e. the position, of an object of interest) in terrestrial vertebrate wildlife research is that, without human monitoring or manipulation, GNSS can provide accurate positioning information on wildlife at any time, in any weather condition, and at any place (Samuel \& Fuller 1996, Spilker 1996a, Friar et al. 2004). Satellite-based positioning is considered especially useful for species that are hard-to-see, nocturnal, or live in remote or rugged terrain because receivers can be programmed to automatically collect many positions over long time periods without human direction (Hulbert \& French 2001). Under ideal conditions, positions should meet the + . 15-meter accuracy claims of the GNSS collar manufacturers (Samuel \& Fuller 1996, Hebblewhite et al. 2007, Villepique et al. 2008). A place has ideal conditions for GNSS positioning if there are no sky obstructions above 15 degrees over the horizon and nothing nearby to cause multipath, although the GNSS error budget has many other components (Meyer et al. 2006). Position error is caused by, among other things, anything in the environment that attenuates (or blocks) the satellite signals, thus weakening the strength-of-figure in the visible constellation, decreasing the signal-to-noise ratio, and causing multipath (Spilker 1996b). GNSS-collar positioning accuracy, therefore, decreases in habitats with dense canopy (Rempel et al. 1995; D'Eon et al. 2002, Hebblewhite et al. 2007, Meyer et al. 2002), sky-obstructing topography, and other solid mass surface features (D'Eon et al. 2002, Friar et al. 2004). The ability of a GNSS collar to acquire a position at all, or to acquire an accurate position, in these GNSS-challenged habitats should be affected by animal activity related to species selection for different habitats (Coelho et al. 2007, Moen et al. 1996, 2001).

Wildlife researchers have identified egregious GNSS-collar errors and their probable sources (Cain et al. 2005). Few researchers, however, have documented more common, less obvious, errors in carefully designed studies focused on the performance and positioning accuracy of GNSS collars before deploying them on wildlife (Graves \& Waller 2006). Researchers also recommend testing GNSS wildlife-tracking collars to determine baseline error ranges in the areas where they will be used before they are deployed on wildlife, but this is rarely done (Lewis et al. 2007). To our knowledge, this is the first GNSS collar accuracy assessment conducted in the GNSS-challenged Patagonian landscape of Torres del Paine National Park, Chile, and also the 
first GNSS-collar positioning accuracy comparison against geodetic-quality control in Torres del Paine National Park. Our goals were to determine the baseline performance of three different manufacturer's GNSS collars and their potential suitability for use on wildlife in Torres del Paine National Park.

\section{Study Área}

Torres del Paine National Park (hereafter TPNP) has an approximate area of $2,300 \mathrm{~km}^{2}$ with elevations from $60 \mathrm{~m}$ to $3000 \mathrm{~m}$. It is located at the eastern edge of the Andes Mountains in the Patagonia Region of Chile (50 $45^{\prime}-51^{\circ} 20^{\prime} \mathrm{S}$; $72^{\circ} 31^{\prime}-73^{\circ}$ $\left.22^{\prime} \mathrm{W}\right)$. TPNP has varied terrain: from flat plains in the lowlands to cliffs on the eastern edge of the Andes Mountains. The area contains glaciers, high mountains, deep valleys, shrubland and grassland communities, unique beech deciduous forests, and even desert. TPNP is typically described as "rugged" terrain (Bank et al. 2002). Many valleys have riparian vegetation and are often enclosed in steep cliffs and hills, resulting in corridors of movement where animals are channeled through canyons and dense vegetation.

\section{MATERIALS AND METHODS}

We contacted fifteen different GNSS collar manufacturers to request their cooperation in testing their equipment. Our solicitations resulted in three positive responses. In 2005, BlueSky (http:// www.blueskytelemetry.co.uk/), Advanced Telemetry Systems (ATS, http://www.atstrack.com/), and SirTrack (http://www.sirtrack.com/) responded, but only SirTrack was able to provide a test collar. In 2006, all three manufacturers provided a test collar. GNSS-collar positions were collected in December and January in both 2005 and 2006.

Four control markers, named TDP1, TDP2, TDP3, and TDP4, were set from 1999 to 2004 by $\mathrm{T}$. Meyer and A. Trani from the University of Connecticut (Fig. 1). We used TDP1, TDP2, and TDP4 in this study. The markers are stamped aluminum

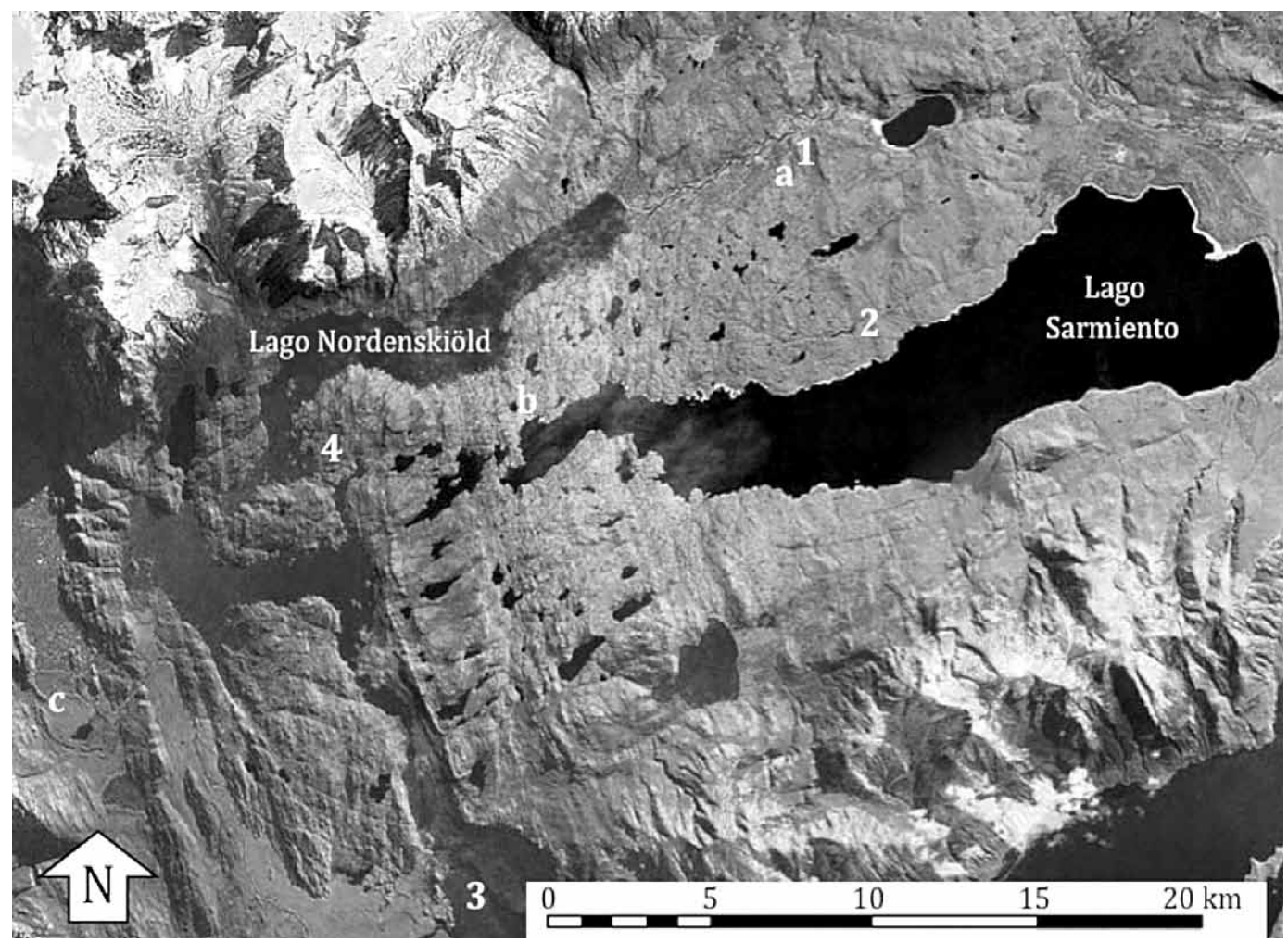

Fig. 1. A panchromatic LandSat 7 ETM satellite image (October 2, 1999) of the Laguna Amarga Sector of Torres del Paine National Park, Magallanes, Chile. Control Markers are labeled with numbers, while the Simulated Moving Animal Corridors (SMACs) are labeled with letters. 
caps set into bedrock outcrops by drilling a borehole, inserting a steel rod into a socket in the base of the cap, setting the cap and rod into the borehole, and cementing them in place. Each marker had minimal sky obstruction (no canopy and little topographic obstruction higher than 15 degrees above the horizon) in its immediate area, resulting in ideal GNSS positioning conditions. The local mountains lay largely to the north. The markers' coordinates (Table 1) were established with dual-frequency, dual-constellation (GPS+GLONASS), carrier phase-observing Javad Legacy and Odyssey GNSS receivers. The survey was controlled by International GNSS Service (IGS) permanent reference stations. Position repeatability at the five-centimeter level was obtained.

\section{Stationary Testing Methods}

The three collars were tested at the control markers. Collars were placed side-by-side on the control markers and operated simultaneously. All positions at each mark were collected on the same day but the marks were occupied on different days. The collars' antennas were placed on the control markers and oriented vertically (at a zenith angle of $0^{\circ}$ ) for two hours and then reoriented horizontally (at a zenith angle of $90^{\circ}$ ) for two hours. Each collar came preprogrammed from the manufacturer with a position-acquisition schedule and we did not have the capability to change the programming in the field before testing. The ATS collar was programmed to collect one position every 30 minutes. The BlueSky collar was programmed to collect one position every five minutes. The SirTrack collar was programmed to collect up to 10 positions every 30 minutes; if the first attempt failed it continued to try and acquire a position each second for 30 seconds.

The collar-determined UTM eastings and northings were subtracted from the control coordinates and then analyzed with ANOVA for directional bias

Table 1. Survey Control Marker Coordinates, UTM WGS 84, zone 18s, meters.

\begin{tabular}{ccc}
\hline Control Mark & Northing & Easting \\
\hline TDP 1 & 4345354.86 & 651121.90 \\
TDP 2 & 4350074.40 & 654186.32 \\
TDP 4 & 4341073.42 & 640278.82 \\
\hline
\end{tabular}

in the north/south or east/west directions indicating whether or not the mean error was zero. There was no a priori reason to suspect there would be biases because the control markers had the same unobstructed sky visibility in all directions.

We used ANOVA tests to determine whether manufacturer, marker, and antenna vertical orientation explained a significant amount of coordinate variability. SirTrack was found to be different, so its data were analyzed separately in the remaining two tests, and the BlueSky and ATS data were pooled. The sample sizes for the tests were different ATS $n=13$, BlueSky $n=81$, and SirTrack $n=66$ due to the different preprogrammed acquisition-schedules from each manufacturer.

We computed a radial Euclidian error distance (in meters) by transforming the collars' output geodetic coordinates into a local topocentric geodetic coordinate system (Meyer 2009, pp. 81) using Wolfram Research Inc.'s Mathematica v.8 computational environment (Wolfram 1999).

\section{Simulated Moving Animal Corridor Methods}

Three common habitats in the Park were selected as simulated moving animal corridors (SMACs), and labeled SMAC1, SMAC2, and SMAC3 (Fig. 1). SMAC1 was in the comparatively open steppe, "Camp Valley" area of TDP. Camp Valley is dominated by open grassland and small shrubs in a wide valley that gently slopes upwards on the northern and southern sides. SMAC2 is in an area known as "Vega Puma". Vega Puma is dominated by scrubland and small patches of deciduous trees 9-15 m high. The Vega Puma Canyon is wide and runs southwest-to-northeast with sections of steep cliff on either side. SMAC3 is in the "Lago Grey" area of TDP near a glacial ice field. Lago Grey is dominated by a mature forest having $10-\mathrm{m}$ to 20-m trees with spreading canopy coverage. The topography has steep and narrow cliffs running in a southeast-to-northwest direction.

We used rapid static positioning (Goad 1996, Parkinson 1996c, Van Sickle 2008) to establish centimeter-accuracy positions at SMAC testing stations against which to assess collar accuracy in places mountain lions (Puma concolor) and guanacos (Lama guanicoe) or huemuls (Hippocamelus bisulcus) could reasonably be expected to frequent. 
Rapid static positioning requires placing one receiver, called a base, atop a 2-m range pole on a reference marker (whose coordinates were previously established with long, static observation sessions) where it continuously collects observations from all satellites in view. Another receiver, called a rover, is carried atop a 2 -m range pole to the testing locations where the rover stops to collect observations simultaneously with the base. This allows the centimeter-accuracy positions, relative to the reference marker, to be determined at each testing location.

Tracking collar testing proceeded as follows. For each SMAC, the base receiver was erected at the reference marker nearest the SMAC. Field personnel carried the rover and a SirTrack collar along the testing route, stopping every 10 minutes to collect 20 minutes of observations at one-second epochs (an epoch is the time interval between observation collections) and one position with the SirTrack collar. The data-collection schedule was in 30 minute intervals because the SirTrack collar was preprogrammed from the manufacturer to acquire one position every 30 minutes.

After the experiment, base and rover observations were downloaded to a desktop computer using PC-CDU data transfer software, and corrected and adjusted using Pinnacle, a GNSS-observation differencing software package, both produced by TOPCON. We used Wolfram Research Inc.'s Mathematica v. 8 for statistical analyses (Wolfram 1999).

Eastings

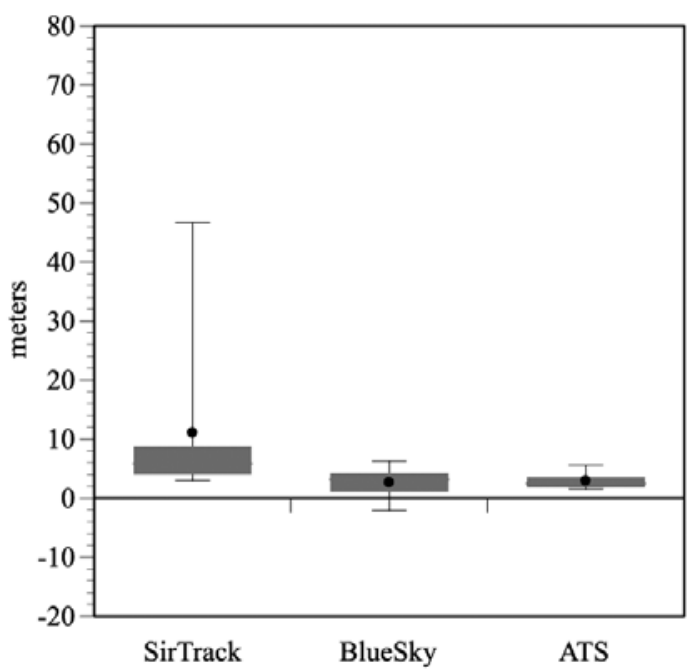

\section{RESULTS}

\section{Stationary Testing Results}

Reference markers were placed in locations where the types and quantity of positioning error they would encounter would be homogeneous. Therefore, we speculated that there would be no significant difference of position error as explained by station. Box plots revealed that the SirTrack collar had four outliers in easting and four outliers in northing coordinates (Fig. 2), from 4 positions collected at TDP4. An ANOVA with Tukey post tests showed that the SirTrack collar was different $(p<0.01)$ from the other two collars in its mean easting coordinate with and without removing the outliers. The SirTrack collar was different from the ATS collar $(p<0.01)$ in both easting and northing coordinates with and without removing the outliers. The SirTrack collar was different $(p<0.01)$ from the BlueSky collar only in its mean northing coordinate when including the outliers, but no differences resulted when the outliers were excluded $(p=0.24)$.

ANOVA tests of coordinate error explained by station were run to test if station explained error. After excluding outliers, SirTrack's means were significantly different in both coordinates $(p<0.01$, both). The pooled coordinates were not significantly different in the mean easting $(p=0.96)$ but were significantly different in the mean northing ( $p<$ 0.01). Fig. 3 shows the distribution of the coordi-

Northings

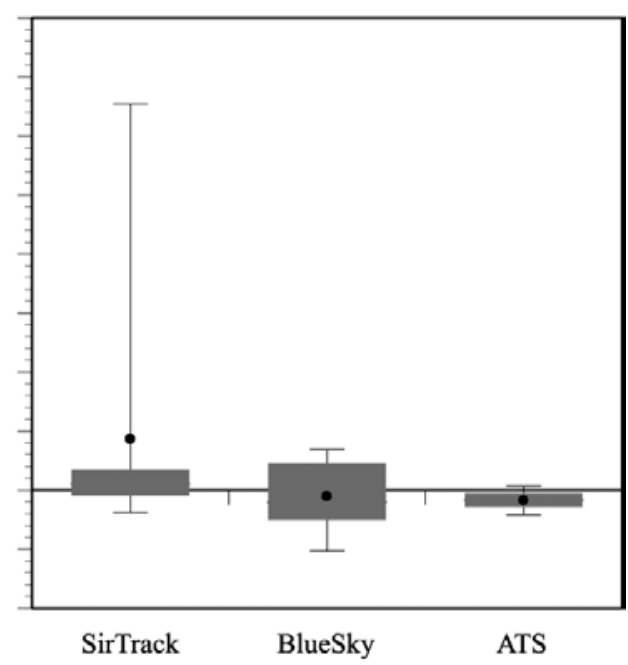

Fig. 2. Box-and-whisker plots of control coordinates subtracted from observed coordinates. 

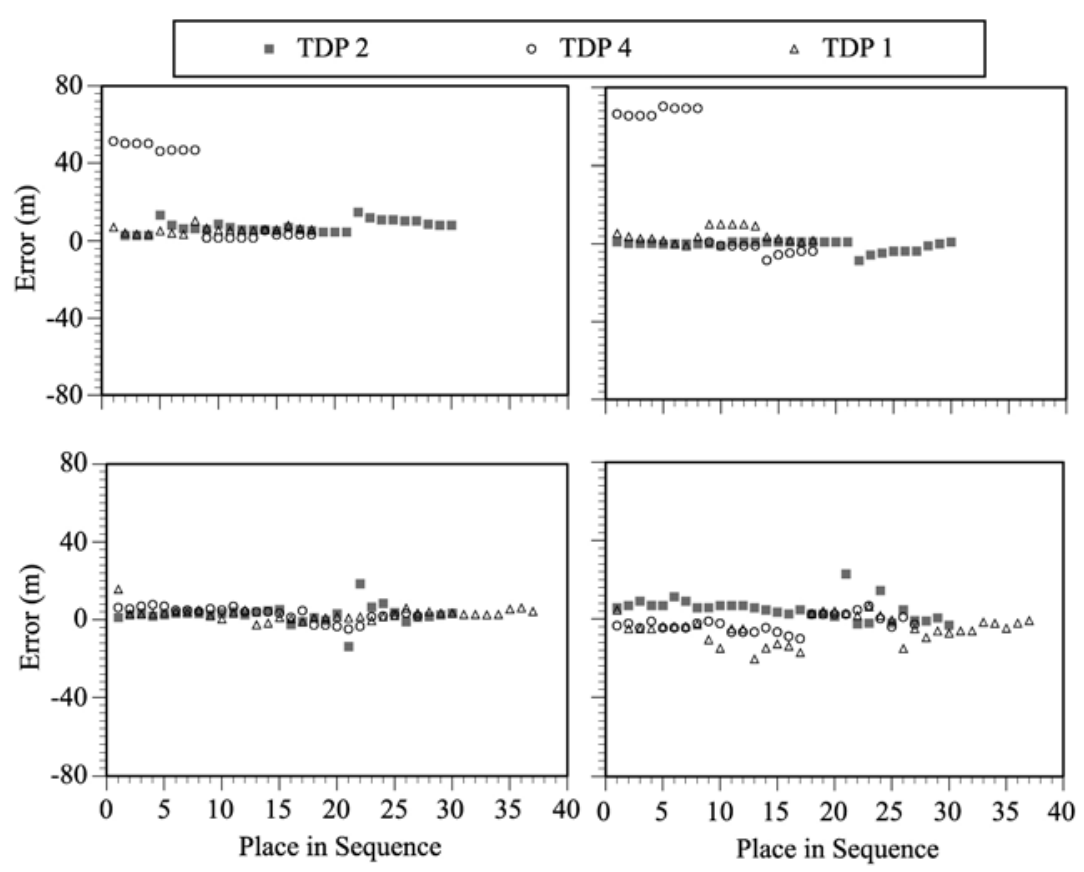

Fig. 3. GPS collar position error distances (meters) computed from control marker coordinates, and analyzed by station; SirTrack plots are across the top, pooled ATS and BlueSky plots are across the bottom. Diamonds indicate TDP 1, circles indicate TDP 2 , squares indicate TDP 4.

nates analyzed by station, for SirTrack and for ATS pooled with BlueSky. The top two panels are the SirTrack collar, while the two bottom panels are the pooled ATS and BlueSky collars. In the SirTrack panels, four outlying positions are evident at TDP4. The remaining coordinates appear evenly spread between zero meters and $30 \mathrm{~m}$ in the eastings and $-10 \mathrm{~m}$ and $+15 \mathrm{~m}$ in the northings. For the pooled collars, the coordinates appear evenly spread $(-5$ $m+20 \mathrm{~m}$ eastings) and (-20 m $+20 \mathrm{~m}$ northings).

Although the tests indicate that station was a factor for the northings, this is mostly likely caused by a lack of data rather than a true effect because: i) although the mountains are to the north, they are below 15 degrees above the receivers' local horizons, which is below the elevation masks in the receivers, ii) the mountains are too far away $(\sim 12 \mathrm{~km})$ to cause multipath, iii) although TDP is fairly far below the equator (which places a limit on how many SVs are visible because the satellite constellation's orbits' inclination to the equator is nominally 55 degrees), any bias caused by this should affect the northing coordinates in the same way, which wasn't the case. Positions determined using the geodetic-grade receivers showed no such biases. If station truly affected coordinate computation in a systematic way, all receivers should be affected, which they were not. Hereafter, we proceed assuming that stations are equivalent.

These GPS collars have omnidirectional antennas, so they should function properly regardless of their spatial orientation. Since an animal might position its body so that the antenna is facing in almost any direction, we tested whether antenna orientation explained position error. The errors are thoroughly mixed, and paired $t$-tests ( $p=0.13$ and $p=0.15$ ) did not reveal significant differences. Hereafter, we proceed assuming antenna orientation does not affect error. Then, we computed position errors equal to collar coordinates minus control coordinates. Fig. 4 shows histograms of error planimetric distances. Table 2 shows the basic descriptive statistics for all three collars.

\section{Simulated Moving Animal Corridor Results}

Out of 45 total attempts, 30 positions (67\%) were acquired. In SMAC1, 21 positions were acqui- 


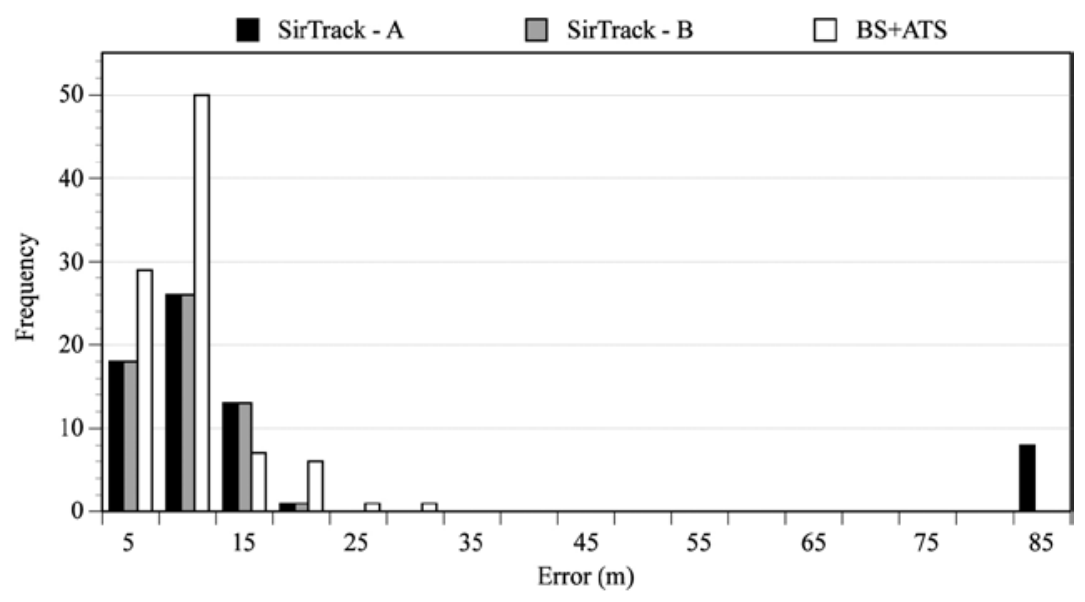

Fig. 4 Error planimetric distances (meters), analyzed by collar. The SirTrack-A errors includes the outliers, the SirTrack-B errors excludes the outliers, and BS+ATS shows errors for BlueSky and ATS pooled together.

red out of $30(70 \%)$ attempted, in SMAC2, six out of seven positions attempted (86\%) were acquired, and in SMAC3 three positions were successfully acquired in eight attempts (38\%). All SMAC error distances were greater than two meters. Twenty six distances were less than 45 meters. The largest values were SMAC1 = $84 \mathrm{~m}, \mathrm{SMAC1}=396 \mathrm{~m}$, SMAC2 $=414 \mathrm{~m}$, and SMAC3 $=528 \mathrm{~m}$. Including outliers, the mean (standard deviation) GNSS collar errors were SMAC1 = $38 \mathrm{~m}(84 \mathrm{~m}), \mathrm{SMAC2}=80$ $\mathrm{m}(163 \mathrm{~m})$, and SMAC3 = $186 \mathrm{~m}(297 \mathrm{~m})$. After removing the three largest errors, mean (standard deviation) error distances were reduced to SMAC1 $=20 \mathrm{~m}(20 \mathrm{~m})$, SMAC2 $=14 \mathrm{~m}(9 \mathrm{~m})$, and SMAC3 $=14 \mathrm{~m}(6 \mathrm{~m})$. The mean SirTrack error across all sites, including outliers, was $61 \mathrm{~m}(133 \mathrm{~m})$, and the mean (standard deviation) error across sites after outlier removal was $19 \mathrm{~m}$ (17 m). Fig. 5 breaks down the distribution of errors by SMAC, revealing one significant outlier in each SMAC.

\section{DISCUSSION}

The ANOVA revealed that the Sirtrack collar's eastings were significantly different from the ATS's and BlueSky's eastings. The Sirtrack's eastings are positively skewed (all above zero), whereas the ATS's and BlueSky's eastings are spread around zero. This trend does not appear in the northings. We identified no cause for this trend. The position computations are performed in Earth-Centered,
Table 2. Error statistics (all distances in meters) computed between GPS collar positions and Control Coordinates.

\begin{tabular}{lccc}
\hline & $\begin{array}{c}\text { ATS } \\
(\mathrm{n}=13)\end{array}$ & $\begin{array}{c}\text { SirTrack } \\
(\mathrm{n}=66)\end{array}$ & $\begin{array}{c}\text { BlueSky } \\
(\mathrm{n}=81)\end{array}$ \\
\hline Mean & 4 & 16 & 8 \\
Std dev & 2 & 25 & 5 \\
Smallest error & 1 & 1 & 2 \\
Largest error & 7 & 84 & 27 \\
Range & 6 & 83 & 25 \\
\hline
\end{tabular}

Earth-Fixed Cartesian coordinates that have no obvious orientation to the cardinal directions, i.e., the position computations cannot systematically bias eastings and not northings everywhere. It is possible that there could be a bias caused by the positioning itself, but, if so, it would be a colossal coincidence that it would manifest as seen. Furthermore, the collars were not systematically aligned to a compass direction as the data were collected, which seems to rule out hardware malfunctions specific to that receiver. Even though the ANOVA results showed that the collars' eastings were different, we suspect that the small number of positions collected contributed to the apparent difference, and, if there were more positions in the computations, the differences would become insignificant. We believe the same holds true for the differences explained by station.

Mean error distances generally increase with increasing canopy coverage and topographic affects (angle-of-elevation and line-of-sight obstructions). Outliers, although obvious in these datasets by virtue 


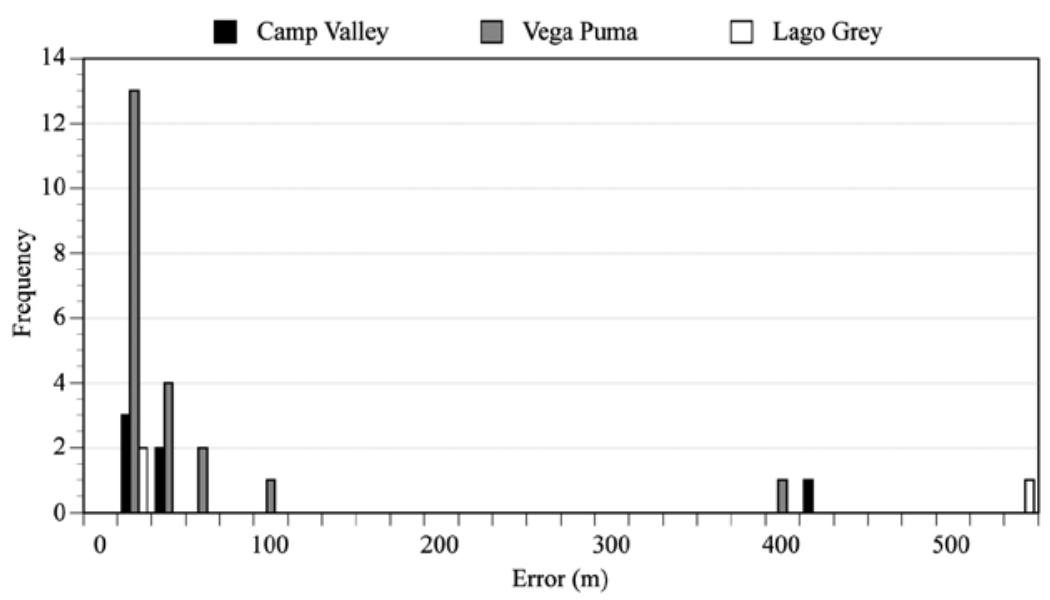

Fig. 5 Histograms of errors by SMAC, from left to right: (a) SMAC 1, Camp valley (b) SAMC 2, Vega puma, and (c) SMAC 3 , Lago Grey.

of comparison to the known control points, might not be as easily identified in datasets from widely ranging animals. If outliers are not identifiable and a mean 101-m error is obtained, it might not greatly affect home range or movement analyses of wideranging species. On the other hand, outliers might be misinterpreted to imply false habitat and landscape usage. Species with small, specialized home ranges and critical habitats might also be misinterpreted. Because many wildlife studies use LANDSAT digital imagery (with a pixel resolution size of $30 \mathrm{~m}$ ), critical habitat and corridor mapping might be overestimated with wide ranging species and miscalculated entirely with highly localized species.

Although the collars' results are disappointing, the bigger picture remains that the observed errors are small compared to the daily movements of the large mammals these collars are intended for. If there is an occasional, undetected, egregious error, it, nevertheless, would likely not invalidate an entire study. Based on these results, we recommend that these GNSS collars can be used with wildlife research in Torres del Paine with considerations for the scale of the analyses and the species under study.

\section{ACKNOWLEDGEMENTS}

We are grateful for BlueSky, Advanced Telemetry Systems, and SirTrack for providing GPS test-collars during this study. Many thanks go to the Chilean Park Service (Corporación Nacional Forestal de Chile, or CONAF) and the staff of Torres del Paine National Park for this opportunity. We are extremely grateful to Hosteria los Torres for providing camping facilities. Individuals who supported us and participated in the data collection include Oscar Guineo, Gladys Garay, and students from the University of Connecticut and the Universidad de Magallanes in the 2004 and 2005 Scientific Research Expeditions. Finally, many thanks to Daniel L. Civco, Professor of Geomatics in the Department of Natural Resources and the Environment at UConn, for his assistance in finding satellite images of the study area.

\section{LITERATURE CITED}

Bank, M.S., R. J. Sarno, N.K. Campbell \& W.L. Franklin 2002. Predation of guanacos (Lama guanicoe) by southernmost mountain lions (Puma concolor) during a historically severe winter in Torres del Paine National Park, Chile. Journal of Zoology, London 258: 215-222

Cain, J.W. III, P.R. Krausmann, B.D. Jansen \& John R. Morgart 2005. Influence of topography and GPS fix interval on GPS collar performance. Wildlife Society Bulletin, 33(3): 926-934

Coelho, C.M., L.F.B. de Melo, M.A.L. Sábato, D.N. Rizel \& R.J. Young 2007. A note on the use of GPS collars to monitor wild maned wolves Chrysocyon brachyurus. Applied Animal Behaviour Science, 105: 259-264 
D'Eon, R.G., R. Serrouya, G. Smith \& C.O. Kochanny 2002. GPS radiotelemetry error and bias in mountainous terrain. Wildlife Society Bulletin, 30: 430-439

Friar, J.L., S.E. Nielsen, E.H. Merrill, S.R. Lele, M.S. Boyce, R.H. Munro, G.B. Stenhouse \& H.L. Beyer 2004. Removing GPS collar bias in habitat selection studies. Journal of Applied Ecology, 41: 201-212

Goad, C. 1996. Surveying with the Global Positioning System. In: Parkinson \& Spilker Vol. II (1996), pp. 501-518

Graves, T.A. \& J.S. Waller 2006. Understanding the causes of missed global positioning system telemetry fixes. Journal of Wildlife Management, 70: 844-852

Hebblewhite, M., M. Percy \& E.H. Merril 2007. Are all global positioning system collars created equal? Correcting habitat induced bias using three brands in the Central Canadian Rockies. Journal of Wildlife Management, 6: 2026-2033

Hulbert, I. A.R. \& J. French. 2001. The accuracy of GPS for Wildlife telemetry and habitat mapping. Journal of Applied Ecology, 38: 869-878

Lewis, J. S., J.L. Rachlow, E.O. Garton, \& L.A. Vierling 2007. Effects of habitat on GPS collar performance: using data screening to reduce location error. Journal of Applied Ecology, 44: 663-671

Meyer, T.H., Bean J, R. Ferguson \& J.Z. Naismith 2002. The Effect of Broadleaf Canopies on Survey-grade Horizontal GPS/GLONASS Measurements. Surveying and Land Information Science, 62(4): 215-224

Meyer, T. H., Roman, D. \& D.B. Zilkoski 2006. What does height really mean? Part IV: GPS Orthometric Heighting. In Surveying and Land Information Science, 66 (3):165-183

Meyer, T.H. 2009. Introduction to Geometrical and Physical Geodesy: Foundation of Geomatics. ESRI Press, 270 pp.

Moen, R., J. Pastor, Y. Cohen \& C. Schwartz 1996. Effects of moose movement and habitat use on GPS collar performance. Journal of Wildlife Management, 60: 659-668
Moen, R., J. Pastor, \& Y. Cohen 2001. Effects of animal activity on GPS telemetry location attempts. ALCES 37(1): 207-216

Moore, D.S. \& G.P. McCabe 1989. Introduction to the practice of statistics. Fourth edition. W. H. Freeman and Co. New York, NY. 828 pp.

Parkinson, B.W. \& Per K Enge 1996c. Differential GPS. In Parkinson \& Spilker Vol. II (1996), pp. 3-50.

Parkinson, B., W. \& J.J. Spilker (eds). 1996. The Global Positioning System: Theory and Applications. Volume I. Progress in Astronautics and Aeronautics, Vol. 163. 793 pages.

Parkinson, B., W. \& J.J. Spilker (eds). 1996. The Global Positioning System: Theory and Applications. Volume II. Progress in Astronautics and Aeronautics, Vol. 164. 643 pages.

Rempel, R.S., A.R. Rodgers \& K.F. Abraham 1995. Performance of a GPS animal location system under boreal forest canopy. Journal of Wildlife Management, 59: 543-551

Samuel, M.D. \& M.R. Fuller 1996. Wildlife Radiotelemetry. In: Brookhout, Theodore A. 1996, pp. 370-418

Spilker, J.J. 1996a. Overview of GPS Operation and Design. In: Parkinson \& Spilker Vol. I. 1996, pp. 29-55

Spilker, J.J. 1996b. GPS Signal Structure and Theoretical Performance. In: Parkinson \& Spilker Vol. I 57-119

Spilker, J.J. 1996c. GPS Navigation Data. In: Parkinson \& Spilker Vol. I. 1996, pp. 121-176

Spilker, J.J. 1996d. Satellite Constellation and Geometric Dilution of Precision. In: Parkinson \& Spilker Vol. I. 1996, pp. 177-208

Van Sickle, J. 1996. GPS for Land Surveyors. Ann Arbor Press, Inc. Chelsea, Michigan. 209 pp.

Villepique, J.T., V.C. Bleich, B.M. Pierce, T.A. Stephenson, R.A. Botta \& R.T. Bower 2008. Evaluating GPS collar error: A critical evaluation of Televilt POSREC - Science collars and a method for screening location data. California Fish and Game.

Wolfram, S. 1999. The Mathematica Book, $4^{\text {th }}$ ed. Cambridge University Press. New York, N.Y. 1470 pp. 
